J. Pestic. Sci., 30(4), 361-367 (2005)

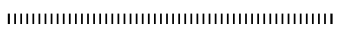

Original Article

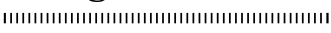

\title{
Identification of the Sex Pheromone of the Citrus Leafminer (Phyllocnistis citrella Stainton, Lepidoptera: Gracillariidae) with a Trial of Control by the Communication Disruption Method
}

\author{
Shaban Ali Mafi, Le Van VAng, ${ }^{\dagger}$ Yoshihisa NAKATA, ${ }^{* *}$ Nobuo OHBAYASHI, \\ Masanobu YAMAMOTO ${ }^{\dagger}$ and Tetsu ANDO ${ }^{\dagger, *}$ \\ Entomological Laboratory, Faculty of Agriculture, Ehime University, Matsuyama, 790-8566 Japan \\ ${ }^{\dagger}$ Graduate School of Bio-applications and Systems Engineering, Tokyo University of \\ Agriculture and Technology, Tokyo, 184-8588 Japan
}

(Received May 30, 2005; Accepted July 5, 2005)

\begin{abstract}
GC-EAD and GC-MS analyses of a pheromone gland extract from virgin females of the citrus leafminer (CLM, Phyllocnistis citrella Stainton) confirmed that the male attractant previously found by random screening tests in a field, (7Z,11Z)-7,11-hexadecadienal (Z7,Z11-16:Ald), is a real pheromone component of CLM. While a field test of lures mixed with extra compounds structurally related to Z7,Z11-16:Ald did not inform candidates for a minor component having a synergistic effect, some compounds, particularly monoenyl derivatives, strongly inhibited the activity of the dienyl pheromone component. Furthermore, two experiments were carried out in citrus orchards to develop a method for disrupting the mating of CLM. In order to estimate the disruptive ability of Z7,Z11-16:Ald and some derivatives, pheromone traps surrounded with septa impregnated with these test compounds were used. However, this first trial was fruitless because the number of captured males actually increased due to the effect of the surrounding compounds such as Z7,Z11-16:Ald. On the other hand, another experiment with polyethylene dispensers containing Z7,Z11-16:Ald revealed a good ability to disrupt the male's orientation, although CLM eggs and larvae on a citrus tender flush did not show any significant difference in the control and treated fields. Monitoring traps caught 27-127 males in one night in control fields from July to September, but hardly any males were caught in either field treated with the dispensers at a density of 500 or 1300 tubes/ha. (C) Pesticide Science Society of Japan
\end{abstract}

Keywords: Phyllocnistis citrella, lepidopteran sex pheromone, dienyl aldehyde, mating disruption, inhibition of male orientation.

\section{INTRODUCTION}

The citrus leafminer, Phyllocnistis citrella Stainton (CLM, Lepidoptera: Gracillariidae), is an important pest of citrus and related Rutaceae almost worldwide. Effective chemical control of CLM is difficult to achieve since the feeding larvae and pupae are protected by the leaf cuticle and the rolled leaf margins. ${ }^{1)}$ So the development of new integrated pest management techniques with pheromonal compounds and selective

* To whom correspondence should be addressed. E-mail: antetsu@cc.tuat.ac.jp

** Present address: Biotechnology Association, Sankei Chemical Co., Fukaya, Saitama, 366-0032 Japan (C) Pesticide Science Society of Japan insecticides is a very desired goal. It has been reported that an analogue compound of the sex pheromone of the pink bollworm moth [(7Z,11Z)-7,11-hexadecadienal, (Z7,Z11-16:Ald)] powerfully attracted the male moths of CLM in Japan. ${ }^{2)}$ The compound was assumed to be at least one component of the sex pheromone of CLM based on its strong attractiveness to males. However, this assumption was doubted because the attractant did not catch any CLM males when tested in other countries (Ujiye, personal communication). When applying Z7,Z11-16:Ald to pest management, it is important to determine the actual pheromone in the virgin female. Therefore, we first carried out the identification of the sex pheromone of CLM. Next, the attractiveness of the CLM pheromone and related compounds was evaluated, and finally, the ability to dis- 
rupt mating was examined in citrus groves.

\section{MATERIALS AND METHODS}

\section{Insects and Pheromone Extraction}

The collection of CLM pupae and all the field experiments were conducted at citrus orchards of the Fruit Tree Research Station of Ehime Prefecture in 2002 and 2003. The pupae were sexed and the female pupae were kept in an incubator (L12:D12 and $28 \pm 1^{\circ} \mathrm{C}$ ) until the adult moths emerged. Terminal abdominal segments of 2- to 3-day-old virgin females were cut off during scotophase and soaked in hexane for $30 \mathrm{~min}$. This extract was subjected to GC-EAD and GC-MS analyses without any purification.

\section{Chemicals}

From (7Z,11Z)-7,11-hexadecadienyl acetate (Z7,Z11-16:OAc) supplied by Shin-Etsu Chemical Co., Ltd. (Tokyo, Japan), Z7,Z11-16:Ald was newly synthesized via oxidation of the corresponding alcohol (Z7,Z11-16:OH). ${ }^{2)}$ The $(7 Z, 11 E)$-isomer (Z7,E11-16:Ald) was prepared by the same procedure from the $(7 Z, 11 E)-7,11$-hexadecadienyl acetate also supplied by Shin-Etsu Chemical Co., Ltd. (Z)-11-Hexadecenal (Z1116:Ald), (Z)-7-hexadecenal (Z7-16:Ald), and their (E)-isomers (E11-16:Ald and E7-16:Ald) were prepared from the corresponding monoenyl alcohol, which had been synthesized for a previous study. ${ }^{3)}$ Pyridinium chlorochromate was used for oxidation on a small scale to make lures for male attraction, and Swern oxidation with dimethyl sulfoxide and oxalyl chloride was used to make Z7,Z11-16:Ald on a large scale for dispensers of mating disruption.

\section{GC-EAD Analysis}

The electroantennogram (EAG) activity of natural and synthetic pheromone components was measured using a gas chromatograph equipped with an electroantennographic detector (GC-EAD). ${ }^{4)}$ The GC was an HP-5890 Series II gas chromatograph (Hewlett-Packard, DE, USA) with a capillary column (DB-23, $0.25 \mathrm{~mm} \times 30 \mathrm{~m}, \mathrm{~J} \& \mathrm{~W}$ Scientific, CA, USA). The carrier gas was He, and samples were injected in a splitless mode. The oven temperature was maintained at $80^{\circ} \mathrm{C}$ for $1 \mathrm{~min}$ and programmed to increase at a rate of $8^{\circ} \mathrm{C} / \mathrm{min}$ up to $210^{\circ} \mathrm{C}$. The effluent from the column was split between a flame ionization detector (FID) and the EAD at a ratio of $1: 1$. An antenna was excised at the base from a CLM male, and a few distal segments were cut off. Each end of the antenna was attached to a droplet of saline solution on an electrode of the EAD device. The EAG activity of each standard (Means \pm SE) was measured with at least five antennae.

\section{GC-MS Analysis}

Analysis by GC combined with mass spectrometry (GC-MS) was conducted with an HP-5973 mass spectrometer interfaced to an HP-6890 gas chromatograph in the electron impact (EI) mode $(70 \mathrm{eV})$. The ion source temperature was $230^{\circ} \mathrm{C}$. Mass spectra $(m / z \quad 30-600)$ were measured twice per second in a cyclic scan mode lasting from 6 to $27 \mathrm{~min}$ after the sample injection using the same column (DB-23), temperature conditions, and carrier gas for the analysis by GC-EAD.

\section{Filed Trapping of Male Moths}

Lures were prepared by applying $100 \mu \mathrm{l}$ of single or multi component hexane solution to individual rubber septa $(8 \mathrm{~mm}$ OD, white rubber; Aldrich, St Louis, MO, USA), and tested using sticky traps $(30 \times 27 \mathrm{~cm}$ bottom plate with a roof, Takeda Chemical Ind. Ltd., Osaka, Japan) set separately by at least $10 \mathrm{~m}$ at $1.5 \mathrm{~m}$ above the ground. A randomized complete design with three replicates of each lure was examined. The number of captured males was counted at least once a week. As a virgin female trap, a cylindrical $(2.5 \times 2.5 \mathrm{~cm})$ screen cage with ten virgin females of 1- to 2-day-old was placed at the center of the trap. In the cage, some small drops of $70 \%$ sugar water were served as a food source. These traps were inspected 2 or 3 days after being set.

In order to evaluate disruptants using rubber septum dispensers, four wires were attached around the sticky trap, ${ }^{5,6}$ i.e., upward, downward, and forward of two windows of the trap holding a rubber septum impregnated with Z7,Z1116:Ald $(1.0 \mathrm{mg})$ in the center of a sticky board as an attractant. The investigated disruptant dissolved in hexane $(100 \mu \mathrm{l})$ was placed into four septa, and the dispensers were connected to the wires at $20 \mathrm{~cm}$ from the center of the trap. The traps of three replicates of each disruptant were placed $1.5 \mathrm{~m}$ above the ground separately by at least $5 \mathrm{~m}$, and inspected every 3 or 4 days.

\section{Formulation of Polyethylene Dispensers and Their Evaluation in the Field}

Together with stabilizers (Sumisorb 300 and Sumilizer BHT, Sumitomo Chemical Co., Ltd., Osaka, Japan, 3\% each), Z7,Z11-16:Ald was formulated into clear polyethylene tubes (20 cm in length), which were used for "Hamaki-con ${ }^{\circledR}$." Each tube contained about $60 \mathrm{mg}$ of the aldehyde and was evaluated in a citrus orchard from July to September in 2003. Three experimental fields were prepared: a low-density field ( 0.08 ha with 40 tubes, 500 tubes/ha), a high-density field ( 0.1 ha with 130 tubes, 1300 tubes/ha), and an untreated field (0.08 ha). Each field was separated by more than $50 \mathrm{~m}$ from the others. A monitoring trap was set at the center of each field with a rubber septum impregnated with Z7,Z11-16:Ald (1.0 mg). To determine the CLM infestation in treated and control fields, 10 tender shoots of each field were cut off and transported to the laboratory. The numbers of eggs and larvae were examined under a binocular microscope. The number of male moths trapped and CLM infestation were examined weekly.

\section{Statistical Analyses}

Data from experiments were subjected to an analysis of variance (ANOVA) and means were separated with Tukey's test. 
Table 1. The average number of CLM males captured by traps baited with ten virgin females or a rubber septum containing the synthetic sex pheromone (1.0 mg of Z6,Z11-16:Ald) in a citrus orchard in various seasons, 2003

\begin{tabular}{|c|c|c|c|}
\hline \multirow{2}{*}{ Period } & \multicolumn{2}{|c|}{ Captured males/trap $(\text { Mean } \pm \mathrm{SE})^{a)}$} & \multirow{2}{*}{$\begin{array}{l}t \text {-test }^{b)} \\
(5 \%)\end{array}$} \\
\hline & Virgin females & Synthetic pheromone & \\
\hline June $28-30$ & $15.2 \pm 3.1$ & $6.7 \pm 3.4$ & NS \\
\hline July $28-30$ & $12.0 \pm 6.7$ & $22.3 \pm 11.3$ & NS \\
\hline Aug. 19-21 & $215.3 \pm 40.2$ & $82.3 \pm 10.2$ & $\mathrm{~S}$ \\
\hline Sept. $18-19$ & $101.5 \pm 16.6$ & $40.0 \pm 3.0$ & NS \\
\hline
\end{tabular}

a) Tested with three traps for each experiment. ${ }^{b)}$ NS: not significant $(p>0.05)$; S: significant $(p<0.05)$.

A paired sampled $t$-test was applied for Tables 1 and 5 .

\section{RESULTS}

\section{Identification of the Pheromone Component}

As shown in Fig. 1, the GC-EAD measurement with a pheromone gland extract of CLM reveals a distinct depolarization on the male antenna at $14.9 \mathrm{~min}$, the retention time $\left(t_{\mathrm{R}}\right)$ when the authentic Z7,Z11-16:Ald elutes from the DB-23 capillary column. Additionally, one weak EAG response by an unknown compound was recorded at $16.1 \mathrm{~min}$, but the $t_{\mathrm{R}}$ was different from that of Z7,Z11-16:OAc (16.4 min) or Z7,Z11$16: \mathrm{OH}(16.8 \mathrm{~min})$. Although the peaks of many unknown

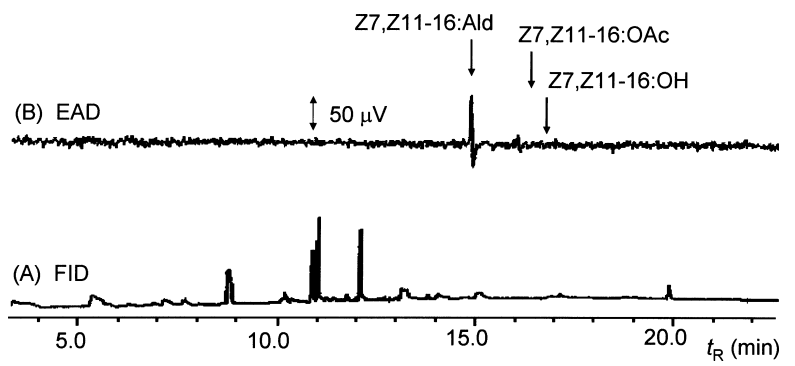

Fig. 1. GC analysis of a crude extract of the pheromone glands of CLM (26 females), with (A) a flame ionization detector (FID) and (B) an electroantennographic detector (EAD) using a DB-23 capillary column $(0.25 \mathrm{~mm} \mathrm{ID} \times 30 \mathrm{~m})$.

compounds were recorded by FID, no traceable amount of Z7,Z11-16:Ald was detected, indicating that the level of Z7,Z11-16:Ald in the pheromone gland was very low.

Next, the pheromone gland extract of CLM was analyzed by GC-MS using the same capillary column. The result is shown in Fig. 2. Synthetic standards of four geometrical isomers of 7,11-diene were detected separately as follows; E7,E11-16:Ald (14.22 min), Z7,E11-16:Ald (14.39 min), E7,Z11-16:Ald (14.42 min), and Z7,Z11-16:Ald (14.58 min). While several peaks were recorded as shown in the total ion chromatogram (TIC) (Fig. 2A), only the elutant at $14.58 \mathrm{~min}$ showed a mass spectrum which was derived from hexadecadienal (Fig. 2B). This spectrum includes some abundant ions derived from impurities around $m / z 165$ and 180 but coincides

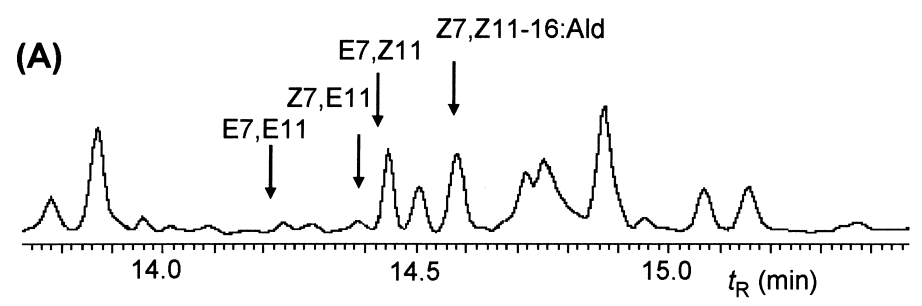

(B)

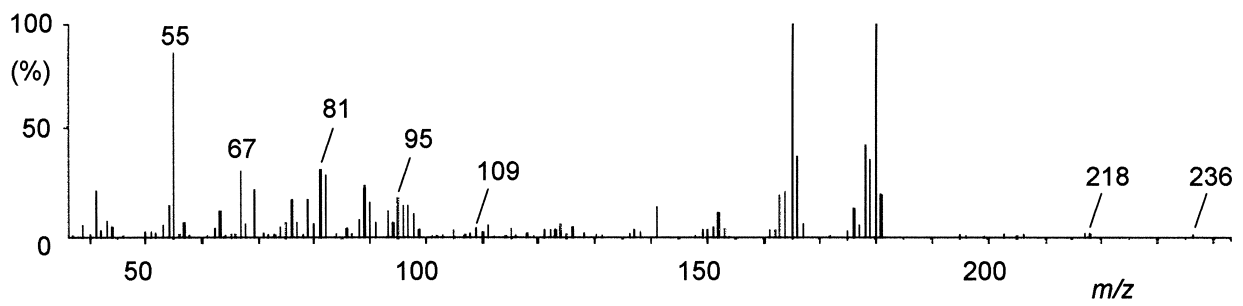

(C)

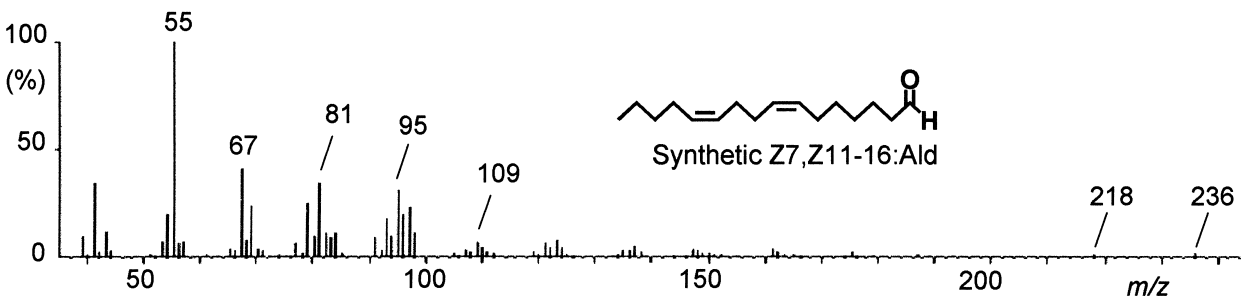

Fig. 2. GC-MS analysis of the pheromone gland extract of CLM (53 females); (A) total ion chromatogram (TIC) and (B) mass spectrum of the compound(s) eluted at $14.58 \mathrm{~min}$, and (C) mass spectrum of the synthetic standard of Z7,Z11-16:Ald. Arrows in the TIC indicate the $t_{\mathrm{R}}$ of Z7,Z11-16:Ald and its three geometrical isomers. 
well with that of synthetic Z7,Z11-16:Ald (Fig. 2C) showing $\mathrm{M}^{+}$at $m / z 236,\left[\mathrm{M}-\mathrm{H}_{2} \mathrm{O}\right]^{+}$at $m / z 218$, and other characteristic fragment ions at $m / z 109,95,81,67$, and 55. Mass chromatograms of these ions indicated a rather low level ( $c a$. $0.01 \mathrm{ng} /$ female) in the pheromone gland.

\section{EAG Activity of the Pheromone and Synthetic Com- pounds}

EAG responses of CLM males to the pheromone extract and synthetic aldehydes are shown in Fig. 3. Among the four geometrical isomers of the dienyl aldehyde, the $(7 Z, 11 Z)$-isomer triggered the greatest response, and $1.0 \mathrm{ng}$ of the synthetic aldehyde stimulated the antennae more strongly than the pheromone extract of 26 females. The antennae also reacted to a monoenyl aldehyde, Z11-16:Ald, but the response was weak.

\section{Trapping of CLM Males Using the Synthetic Pheromone and Virgin Females}

Table 1 shows the number of males captured by the traps baited with the synthetic sex pheromone (Z7,Z11-16:Ald) or virgin females in a citrus orchard in different seasons. There were no significant differences in ability to attract males between the rubber septum containing $1 \mathrm{mg}$ of Z7,Z11-16:Ald and ten virgin females in June, July and September, but the males were more strongly attracted by the females than the synthetic pheromone in August, a season of high population density.

\section{Attraction of Males to the Synthetic Pheromone Mixed with Related Compounds}

The effects of compounds structurally related to Z7,Z1116:Ald on the pheromone activity were examined in the field. Table 2A shows the male attraction of $1: 1$ mixtures of Z7,Z11-16:Ald and each of four related compounds Z7,E1116:Ald, (Z7,Z11-16:OAc, Z7,Z11-16:OH, and Z11-16:Ald), and Table $2 \mathrm{~B}$ shows the results for $1: 1-1: 0.1$ mixtures of Z7,Z11-16:Ald and each of the monoenyl aldehydes (Z716:Ald, Z11-16:Ald, E7-16:Ald, and E11-16:Ald). No compounds indicated a synergistic effect on the attraction of males to the sex pheromone at the tested mixing ratios, but almost all of the mixtures significantly reduced the number of captured males. These experiments indicated that the inhibitory effect of monoenyl aldehydes (Z11-16:Ald and E1116:Ald) was greater than that of the geometrical isomer and functional derivatives of the dienyl pheromone.

\section{Effect of Related Compounds Surrounding the Pheromone Trap}

The attraction of the CLM males to traps surrounded with septum dispensers as disruptants is shown in Table 3. Each trap in this experiment was baited with a 1-mg septum of the synthetic pheromone, Z7,Z11-16:Ald, and surrounded with four 3-mg septa of the pheromone or one of its related com-

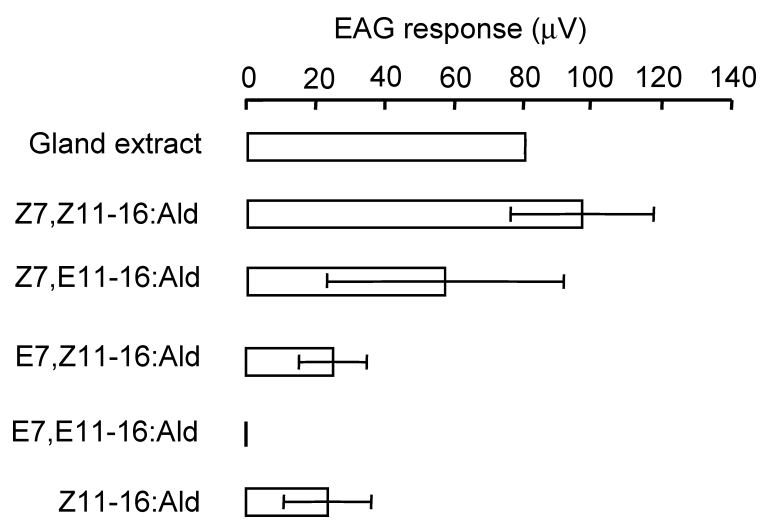

Fig. 3. EAG responses of CLM males to a pheromone extract (26 females) and synthetic standards (1.0 ng) of Z7,Z11-16:Ald, its three geometrical isomers, and Z11-16:Ald.

pounds (Z7,E11-16:Ald, Z7,Z11-16:OAc, Z7,Z11-16:OH, and Z11-16:Ald). There was no significant reduction in the number of captured male moths under the influence of the chemicals tested. Unexpectedly, the placement of the rubber septa containing Z7,Z11-16:Ald caused a remarkable rise in the number of captured males compared with the trap with no disruptants. The septa of Z7,Z11-16:Ald placed around the

Table 2. Capture of CLM males by Z7,Z11-16:Ald alone and mixed with a related compound in a citrus orchard, tested from (A) Sept. 30 to Oct. 15, 2002 and (B) Sept. 16 to Oct. 14, 2003

\begin{tabular}{|c|c|c|}
\hline $\begin{array}{l}\text { Lure } \\
\text { chemical (mg/septum) }\end{array}$ & $\begin{array}{c}\text { Captured males/week/trap } \\
(\text { Mean } \pm \mathrm{SE})^{a)}\end{array}$ & $\begin{array}{l}\text { Inhibition } \\
\qquad(\%)^{b)}\end{array}$ \\
\hline \multicolumn{3}{|l|}{ Z7,Z11-16:Ald (1.0) } \\
\hline (A) + none & $58.1 \pm 16.8 \mathrm{a}$ & - \\
\hline +Z7,E11-16:Ald (1.0) & $21.7 \pm 8.4 \mathrm{c}$ & 63 \\
\hline$+\mathrm{Z7,Z11-16:OAc}(1.0)$ & $16.8 \pm 3.5 \mathrm{~cd}$ & 71 \\
\hline +Z7,Z11-16:OH (1.0) & $41.3 \pm 16.1 \mathrm{~b}$ & 29 \\
\hline +Z11-16:Ald (1.0) & $11.2 \pm 2.8 \mathrm{~d}$ & 81 \\
\hline (B) + none & $79.8 \pm 22.4 \mathrm{a}$ & - \\
\hline +Z7-16:Ald (0.1) & $67.9 \pm 19.6 \mathrm{a}$ & 15 \\
\hline +Z7-16:Ald (0.5) & $25.2 \pm 5.6 \mathrm{ab}$ & 68 \\
\hline +Z7-16:Ald (1.0) & $30.8 \pm 9.1 \mathrm{ab}$ & 61 \\
\hline +Z11-16:Ald (0.1) & $41.3 \pm 10.5 \mathrm{ab}$ & 48 \\
\hline +Z11-16:Ald (0.5) & $39.2 \pm 9.8 \mathrm{ab}$ & 51 \\
\hline +Z11-16:Ald (1.0) & $44.8 \pm 16.1 \mathrm{ab}$ & 44 \\
\hline +E7-16:Ald (1.0) & $47.6 \pm 17.5 \mathrm{ab}$ & 40 \\
\hline +E11-16:Ald (1.0) & $4.9 \pm 0.7 b$ & 94 \\
\hline
\end{tabular}

${ }^{a)}$ Tested with three traps for each lure. Numbers within each test followed by a different letter are significantly different at $p<0.05$ by Tukey's test. ${ }^{b)}$ Inhibitory activity (\%) was calculated as (Nun-Nmix)/Nun $\times 100$, where Nun and Nmix are the numbers of males captured by the traps with Z7,Z11-16:Ald alone and mixed with a related compound. 
Table 3. Capture of CLM males by traps containing an attractant (septum baited with $1.0 \mathrm{mg}$ of Z7,Z11-16:Ald) and disruptants (four septa/trap) in a citrus orchard from Sept. 30 to Oct. 21,2002

\begin{tabular}{lc}
\hline $\begin{array}{l}\text { Disruptant } \\
\text { chemical (mg/septum) }\end{array}$ & $\begin{array}{c}\text { Captured males/week/trap } \\
(\text { Mean } \pm \text { SE) })^{a)}\end{array}$ \\
\hline None & $8.4 \pm 1.4 \mathrm{~b}$ \\
Z7,Z11-16:Ald (3.0) & $23.8 \pm 3.5 \mathrm{a}$ \\
Z7,E11-16:Ald (3.0) & $7.0 \pm 1.4 \mathrm{~b}$ \\
Z7,Z11-16:OAc (3.0) & $10.5 \pm 2.1 \mathrm{~b}$ \\
Z7,Z11-16:OH (3.0) & $9.1 \pm 2.1 \mathrm{~b}$ \\
Z11-16:Ald (3.0) & $4.2 \pm 0.7 \mathrm{~b}$ \\
\hline
\end{tabular}

${ }^{a)}$ Tested with three traps per chemical. Numbers followed by a different letter are significantly different at $p<0.05$ by Tukey's test.

traps seemingly did not play a role in the disruption but acted as an attractant.

6. Disruption of Mating Communication in Fields Permeated with Synthetic Pheromone

The attraction of male moths to the monitoring traps in control orchards and areas permeated with Z7,Z11-16:Ald, which was released from polyethylene dispensers, is shown in Table 4. Though the males were counted every week, this table summarizes the data for every second week. From July to Septem-

Table 4. The numbers of CLM males captured per night in citrus orchards untreated (control) and treated with polyethylene dispensers containing $60 \mathrm{mg}$ of the synthetic pheromone (Z7,Z11-16:Ald) at (A) 500 tubes/ha and (B) 1300 tubes/ha in $2003^{a)}$

\begin{tabular}{lccc}
\hline & \multicolumn{2}{c}{ Captured males/night ${ }^{b)}$} & $\begin{array}{c}\text { Disruption } \\
\text { Period }\end{array}$ \\
\cline { 2 - 3 } & Control (Nc) & Treated (Nt) & $(\%)^{c)}$ \\
\hline (A) July 22-29 & 50.4 & 0.1 & 99.7 \\
Aug. 5-12 & 32.9 & 0.1 & 99.6 \\
Aug. 19-26 & 70.0 & 0.4 & 99.4 \\
Sept. 2-9 & 51.0 & 0.4 & 99.2 \\
(B) July 24-31 & 27.0 & 0.1 & 99.5 \\
Aug. 7-14 & 120.0 & 0.6 & 99.5 \\
Aug. 21-28 & 72.0 & 0.3 & 99.6 \\
Sept. 4-11 & 127.1 & 0.1 & 99.9
\end{tabular}

${ }^{a)}$ Dispensers were placed on July 22 for test A and July 17 for test B. ${ }^{b)}$ Males were captured by the traps baited with synthetic Z7,Z11-16:Ald (1.0 mg/septum). ${ }^{c}$ Disruption of orientation $(\%)$ was calculated as $(N c-N t) / N c \times 100$, where $N c$ and $N t$ are the numbers of males captured in the control and treated fields.
Table 5. The numbers of CLM eggs and larvae in citrus orchards untreated (control) and treated with polyethylene dispensers containing the synthetic pheromone (Z7,Z11-16:Ald) at (A) 500 tubes/ha and (B) 1300 tubes/ha in 2003

\begin{tabular}{lrrrrr}
\hline & \multicolumn{2}{c}{ Eggs/flush (Mean \pm SE) } & & \multicolumn{2}{c}{ Larvae/flush (Mean \pm SE) } \\
\cline { 2 - 3 } \cline { 6 - 6 } Day & Control & Treated & & Control & Treated \\
\hline (A) July 22 & $5.1 \pm 1.1$ & $3.4 \pm 0.7$ & & $15.3 \pm 4.2$ & $9.8 \pm 1.5$ \\
Aug. 5 & $64.6 \pm 7.2$ & $48.4 \pm 4.9$ & & $0.4 \pm 0.4$ & $0.7 \pm 0.4$ \\
Aug. 19 & $35.0 \pm 8.7$ & $44.2 \pm 9.6$ & & $32.7 \pm 4.0$ & $17.2 \pm 2.1$ \\
Sept. 2 & $8.7 \pm 1.8$ & $12.7 \pm 2.2$ & & $17.1 \pm 2.4$ & $13.9 \pm 3.2$ \\
Sept. 16 & $5.2 \pm 1.9$ & $2.5 \pm 0.9$ & & $11.8 \pm 2.3$ & $9.5 \pm 0.9$ \\
(B) July 17 & $2.5 \pm 0.7$ & $7.2 \pm 2.4$ & & $8.3 \pm 1.3$ & $8.8 \pm 2.7$ \\
July 31 & $6.6 \pm 2.7$ & $6.0 \pm 2.2$ & & $11.8 \pm 1.5$ & $8.9 \pm 1.8$ \\
Aug. 14 & $37.6 \pm 9.2$ & $41.0 \pm 9.5$ & & $39.2 \pm 7.9$ & $42.1 \pm 7.9$ \\
Aug. 28 & $17.7 \pm 6.8$ & $13.0 \pm 2.8$ & & $32.3 \pm 7.7$ & $21.0 \pm 6.4$ \\
Sept. 11 & $9.0 \pm 2.1$ & $10.5 \pm 2.1$ & & $29.4 \pm 5.6$ & $30.6 \pm 4.3$ \\
\hline
\end{tabular}

${ }^{a)}$ Dispensers were placed on July 22 for test A and July 17 for test B.

ber, the population of CLM was very high in citrus orchards in Ehime, and the pheromone trap caught about 27-127 males in one night in the control fields. However, hardly any males were caught in the field treated with the dispenser at the level of 500 or 1300 tubes/ha. Therefore, quite a high level of disruption of sexual communication, more than $99 \%$, was recorded. On the other hand, no significant difference was observed in the frequency of eggs and larvae per tender flush in control and disruptant-treated fields ( $t$-test, $\mathrm{df}=8, p>0.05)$, as shown in Table 5. In August, the number of eggs and larvae increased in the treated field to the same degree observed in the control field.

\section{DISCUSSION}

A series of random screening tests had revealed that $(7 Z, 11 Z)$ 7,11-hexadecadienal (Z7,Z11-16:Ald) strongly attracted the male moths of the citrus leafminer (CLM) in Japan. ${ }^{2)}$ In this study, GC-EAD and GC-MS analyses of pheromone gland extracts confirmed that virgin females actually produced dienyl aldehyde, as shown in Figs. 1 and 2. The 7Z,11Z configuration of two double bonds was determined by comparing the chromatographic behavior on the capillary GC column (Fig. 2) and EAG activity of the natural pheromone (Fig. 3) with those of synthetic geometrical isomers. The inactivity of Z7,Z1116:Ald in foreign countries might be due to a different pheromone system of foreign strains. The 7,11-dienyl aldehyde is a new compound and has not been identified in lepidopteran females. In the family of Gracillariidae, sex pheromones of 11 species have been reported. ${ }^{7-9)}$ While two Gracillariidae species secrete aldehydes; i.e., E11-16:Ald in the tea leafroller, Caloptilia theivora ${ }^{10)}$ and $(8 E, 10 Z)-8,10-$ 
tetradecadienal in the horse-chestnut leafminer, Cameraria ohridella ${ }^{11)}$ the pheromone components of other species are acetates and alcohols. Even the titer of the main pheromone component is very low, and information on minor components is thus limited. The lure baited only with Z7,Z1116:Ald, however, attracted the males so strongly that mixing of any other compounds will be unnecessary to monitor the field population of the CLM adults if minor components are really produced by the females.

Preliminary field tests in a copse in Tokyo had indicated that the addition of the acetate and alcohol derivatives to Z7,Z11-16:Ald decreased the number of CLM males caught. ${ }^{2)}$ Our experiments in a citrus orchard in Ehime Prefecture confirmed the previous result: these derivatives, which might not be produced by females as an extra pheromone component, inhibited the activity of Z7,Z11-16:Ald. Furthermore, Z1116:Ald and E11-16:Ald also inhibited the attraction strongly when they were mixed with Z7,Z11-16:Ald in a $1: 1$ ratio (Table 2). These results suggest that the male moths can distinguish the pheromone component and structurally related compounds and recognize the latter to be different odors such as pheromone components secreted by other species.

The mating disruption method to control pest insects by using sex pheromones has proven successful for several kinds of lepidopteran species in crop fields, orchards, vineyards, and forests. ${ }^{12,13)}$ For reproductive isolation, each lepidopteran species has established a species-specific pheromone system, which is composed of multiple components mixed in a special ratio. Based on the natural pheromone system of the target insect, compounds used for the disruption have been selected after trial and error. Mimicry of the natural pheromone system is generally expected to be best for both attraction and disruption, but the mating disruptant "Hamaki-kon ${ }^{\circledR} "$ targeting several leafroller moths includes only one compound, $(Z)$ 11-tetradecenyl acetate, which is a common component of their pheromones. Recently, it was reported that the sexual communication of the Japanese giant looper, a geometrid species with an epoxyalkadienyl pheromone, was effectively disrupted by positional isomers, which inhibited the activity of the synthetic pheromone when mixed." This finding suggests that some inhibitors of pheromones may also be available as a mating disruptant. In the experiment, the ability of the candidates to act as a disruptant was conveniently evaluated by a method utilizing rubber septa, which had been proposed by McDonough et al. ${ }^{5)}$ In the case of CLM, however, candidates for a mating disruptant could not be found with septum dispensers. Namely, the number of captured males was unexpectedly high, as shown in Table 3.

Next, Z7,Z11-16:Ald was sealed into polyethylene tubes and a citrus orchard was permeated with the synthetic pheromone. The effect of the dispensers was remarkable in that hardly any male moths were attracted to the trap baited with Z7,Z11-16:Ald after permeation of the pheromone (Table 4), indicating a near-perfect disorientation to a pheromone source. As reported before, the reduction or elimination of trap captures in pheromone-treated cropping systems has been associated with a reduction in pest density and damage. ${ }^{12)}$ In spite of our good results with male trapping, no significant difference in population density at the immature stages (eggs and larvae) of CLM was unfortunately observed between the pheromone-treated field and the control plot (Table 5). The mating disruption of CLM could not be evaluated directly by experiments with tethered or caged virgin females. In other species, mating can be recognized by the presence of a spermatophore produced after mating. But the CLM moth is too small. Furthermore, even the females recovered from the control field, which might have mated, did not lay eggs after being released into a container with citrus flushes in the laboratory.

The efficacy of this tactic is related principally with the motility of mated females in the area to be managed, the initial population levels of the pest, and the release characteristics of the formulation. ${ }^{12)}$ Area-wide pest management tactics, such as mating disruption, require relatively large plot sizes to be effective. ${ }^{14)}$ Our field trials in about 0.1 hectare orchard plots were thought to be too small to prevent the immigration of fertile females into the pheromone-treated plots from adjacent sections of untreated orchards. It has been reported that many CLM males were caught by attractant traps placed in the copse at a distance of 200-300 $\mathrm{m}$ from the nearest citrus trees. ${ }^{15)}$ The failure to reduce the level of infestation is thought to be due to this behavior of female moths. Another conceivable explanation is the high population of CLM at the beginning of the test. Mating disruption can fail when the population density is very high because of accidental encounters of males and females even though their communication is disrupted.

This is our first attempt to evaluate the mating disruption tactic as a method of controlling CLM in a citrus orchard. Although the primary result was not promising, several factors, such as population density, number of generations, disruptant formulation, movement behavior, and field areas, should be considered in future trials. Further research needs to be carried out on these particular factors.

\section{ACKNOWLEDGMENTS}

The authors are grateful to the manager of the Fruit Tree Research Station of Ehime Prefecture for offering the citrus orchards for this study and Dr. F. Mochizuki of Shin-Etsu Chemical Co., Ltd. for supplying dienyl acetate and formulating a synthetic pheromone.

\section{REFERENCES}

1) J. Knapp, G. Albrigo, H. Browning, R. Bullosk, J. Heppner, D. Hall, M. Hoy, R. Nguyen, J. E. Pena and P. A. StanslyInst: "Citrus Leafminer, Phyllocnistis citrella Stainton: Current Status in Florida-1995," published by Florida Cooperative Extension Service, Inst. Food Agric. Sci., Univ. Florida, Gainesville, 1995. 
2) T. Ando, K. Taguchi, M. Uchiyama, T. Ujiye and H. Kuroko: Agric. Biol. Chem. 49, 3633-3635 (1985).

3) T. Ando, S. Yoshida, S. Tatsuki and N. Takahashi: Agric. Biol. Chem. 41, 1485-1492 (1977).

4) D. L. Struble and H. Arn: "Techniques in Pheromone Research," ed. by H. E. Hummel and T. A. Miller, Springer-Verlag, New York, pp. 161-178, 1984.

5) L. M. McDonough, H. G. Davis, P. S. Chapman and C. L. Smithhisler: J. Chem. Ecol. 20, 171-181 (1994).

6) K. Ohtani, Witjaksono, T. Fukumoto, F. Mochizuki, M. Yamamoto and T. Ando: Entomol. Exp. Appl. 100, 203-209 (2001).

7) T. Ando: http://www.tuat.ac.jp/ antetsu/LepiPheroList.htm

8) A. M. El-Sayed: http://www.pherobase.com/
9) P. Witzgall, T. Lindblom, M. Bengtsson and M. Tóth: http://www-pherolist.slu.se/cgi-bin-pherolist/pherolist.cgi

10) T. Ando, K. Taguchi, M. Uchiyama and T. Horikawa: Agric. Biol. Chem. 49, 233-234 (1985).

11) B. Kalinova, A. Svatos, J. Kindl, O. Hovorka, I. Hrdy, J. Kuldova and M. Hoskovec: J. Chem. Ecol. 29, 387-404 (2003).

12) R. T. Cardé and A. K. Minks: Annu. Rev. Entomol. 40, 559-585 (1995).

13) T. Ando, S. Inomata and M. Yamamoto: Top. Curr. Chem. 239, 51-96 (2004)

14) J. C. Schneider: Environ. Entomol. 18, 868-874 (1989).

15) T. Ujiye: Bull. Fruit Tree Res. Stn. 18, 19-46 (1990). 